will at once cause the whole kite to be driven al ple is derived directly the almost equally well-estab- the stream The one side, and thus in a variable wind the kite will be ple ished doctrine that to pollute a public stream is to loving from side to side. Directly, how ever, we suspend the rod by two strings, it is apparent
that no shifting of the weight or pressure can cause it to move. (See Fig. 5, No. 4.)
Tail. -It may be as well to inquire into the raison d'être of the tail. It is not likely to have been applied to kites
all these years without some reason. Now we know all these years without some reason. Now we know that a badly constructed kite is liable to turn over and can this be prevented? If the lower end can be kept weight were attached to the bottom of the kite, any
irregular movement would set it swinging like a penirregular movement would set it swinging like a pen-
dulum, and this action would probably be increased until the kite revolved right round. Moreover, the weight would simply tend to pull the kite straight
down ward toward the ground. On the other hand, if a long, light tail were attached so as to be driven back by
the wind, it would have a tendency to pull the kite flat. By combining the two, judiciously adding weight to a
long tail, the desired result may be obtained of rectifying the faults of a badly constructed kite.
It is of ten difficult to get practice to ayree with theory. Thus, for instance, according to theory, if the wind is blowing about 50 miles an hour, the presthe rate of 12 lb. per square foot. Thus on 100 square
feet it should be $1,200 \mathrm{lb}$. But if the angle be infeet it should be $1,200 \mathrm{lb}$. But if the angle be in-
clined, even to $30^{\circ}$ with thehorizon, the normal should be 0.8 of this, that is, $960 \mathrm{lb}$. Practically, however,
though I have had out kites to test their pull during strong gales, I have no record of a 100 foot kite ever pulling more than $250 \mathrm{lb}$. on the string, and this amount
is quite exceptional. When considering what weight can be lifted by a
kite, and to what height it can be raised, the forces acting on the string must be considered. These forces
are the weight of the line and the presence of the wind more horizontal near the ground and more perpendicgent to the string (commonly called the "pull) may be divided into two forces of "lift" and "drift," that is, a force acting vertically upward and one acting horizonbe understood that the "lift" is greater in proportion may become so great near the ground as to pull the
line horizontally, and not even lift it off the ground. But on comparatively short lines and in a good wind,
this curve is not of importance. We have, however, to consider the effect of hanging a heavy weight on
the line. That portion above the weight will remain the line. That portion above the weight will remain
at the angle caused by the pull of the kite. But the angle of the string below can be readily found. The above paper was read before the Society
Arts and published in the Journal of the society.

\title{
SEWAGE DISPOSAL.*
}

By Benjamin F. LA RuE.

THE growth of urban population has been very rapid during recent years, showing a remarkable in. crease in the population of nearly all cities and towns,
but more especially of the large cities. This condition the civil engineer working along the lines of water tion greatly augments the flood of sewage poured into the streams, polluting the natural sources of water
supply, and also intensifies, to a corresponding extent, the demand for pure water.
Sewage is the term applied to the solid and liquid
wastes of the human economy, as well as to street washings and factory wastes, and also to the water
combined with them for the purpose of removal. The popular idea regarding sewage is simply that it is entirely out of sight: and the old principle of out of
sight out of mind applies. So long as the sewage does sight out of mind applies. So long as the sewage doe attention.

This attitude of the popular mind in regard to sew-
age is radically wrong and has much retarded the development of sewerage as a science. The waste of the human system is as certainly a vital and unavoidable
fact of existence as is the food on which it suosists fact of existence as is the food on which it suosists ; but should be met fairly and dealt with nor ignored, buts.
upon its merits. In most country districts and small villages, and in
many outlying suburbs. the sewage is discharged into vaults and cesspools, where it remains to putrefy, contaminating the surrounding earth and atmosphere. further attention. In cities, the sewage is removed promptly by the sewers before offensive conditions can arise. So far as the popular mind is concerned, it has
disappeared : what more can be desired? That the sewers are merely conduits for removing the sewage to
other localities, and that the sewage thus removed may produce offensive, unsanitary and even dangerous tures of the matter having little popular interest. to discharge it into the nearest stream or other body water. This method of disposal is convenient and
cheap, and, under proper conditions, is permissible If, however, where this method of disposal is emsmall fraction of the total volume, the water may become so polluted as to be not only wholly unfit for any domestic use, but also a dangerous menace to towns lower down. The objections of such towns to the potthat have in some cases been instituted to prevent it, forms of sewage disposal. stream on which his realty is situated flow past his domain in its natural course and condition is an old and
well-established principle of law $;$ and from this princi* From Home Study Magazine.

the stream. The greater the comparative volume of exposure to the atmosphere--the more rapid and ef
ex fectual will be the purification. The degree of purifcation that can be obtained by this method of disposal is quite uncertain. however, and it would be extremely
hazardous to discharge untreated sewage into a stream hazardous to discharge untreated sewage into a stream used as a source of public water supply. It is safe to
state that this method of disposal is employed in very many cases where it ought not to be. many cases where it ought not to be. of the solid matter and, by some processes, a portion of charging it into a stream or other body of water. The
effluent, though by no means approximating pure water. is much less objectionable than the original sewage. The degree of clarification obtained will depend upon the process employed and the thoroughness
of its application. Three general processes of clarification are employed, namely, sedimentation, mechanical filtration and chemical precipitation. By the process of sedimentation, called also subsi-
dence, the sewage is collected in tanks or reservoirs and allowed to stand until the solids have settled to the bottom, after which the water is drawn off slowly,
discharging into a stream or body of water. The effluent, though somewhat clarified, still remains highly charged with impurities.

By the ordinary processes of mechanical filtration, the sewage is simply passed through filters or screens of various kinds. Such processes remove a larger proby subsidence, but leave the effluent still very imChemical preeipitation is the direct outgrowth of
unsatisfactory sedimentation. The sewage is collected in tanks or reservoirs, and with it are mixed certain
chemical solutions which precipitate not only the solid natter but also a portion of the matter held in solu-
tion. Various chemical processes are employed, a large number of which have been patented. The effluent from sewage clarified by any process of chemical precipitation is, however, far from being pure water, and is stream. Moreover, the addition of the chemicals used is more or less deleterious to the water. This method
of purification is not of itself sufficient where the

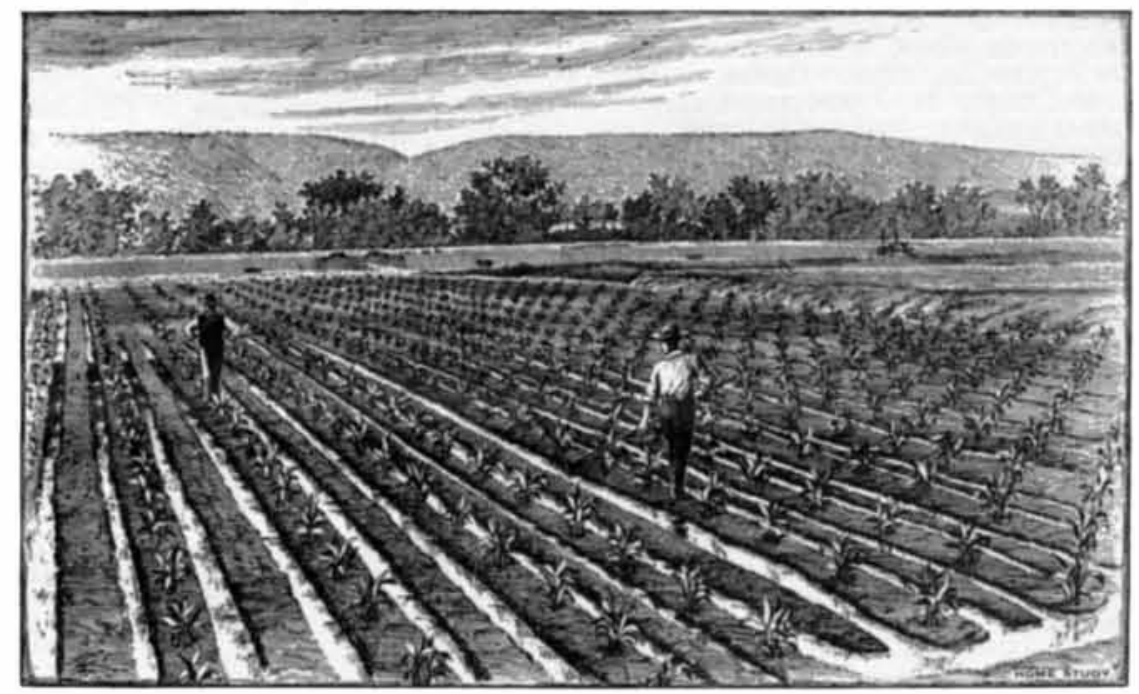

VIEW OF A CORNFIELD ILLUSTRATING IRRIGATION BY SEWAGE.

ber of sewage purification plants have been estabobtained have been, in most cases, highly satisfactory.
o Indeed, so high a degree of purification has been
reached in some cases as to render the purified sewage effuent chemically purer than the average supply of drinking water, and there appears to be no reason, other than popular sentiment, why such a purified The very valuable experiments of the Massachusetts State Board of Health have shown that there is no
difficulty in removing from 95 to $991 / 2$ per cent. of the organic impurity. In view of the great importance of
the subject, it will be of interest to notice briefly the the subject, it will be of interest to notice briefly th the means employed for purification.

Those methods of disposal that have been tested on any considerable scale, and have proved to a reasona-
ble degree successful, may be classified as natural disposal, clarification and application to the soil. Space
permits here only a brief notice of these different permits here only a brief notice of these different
methods of disposal. Natural disposal and dilution are terms sometimes used to designate the practice of discharging sewage
directly into a stream or other body of water without previous treatment. This method of disposal, being both cheap and convenient, has been extensively em-
ployed, and. under proper conditions, its results may be neither offensive nor unsanitary. When untreated
sewage is discharged into a stream of water, the water sewage is discharged into a stream of water, the water
immediately below the sewer outlet will be rendered volume in comparison with the volume of sewage discharged into it, and is sufficiently in motion, exposing it to the action of the atmosphere, a change will take
place and the water will gradually become purified, so that, at a distance of a few miles below the sewer out-
let, all traces of the sewage will have disappeared. let, all traces of the sewage will have disappeared.
Not only will the sewage become very highly diluted
by the comparatively great amount of water, but a
certain degree of actual change, or purification, will also take place.
This change, which is sometimes called self-purification, is due to several causes. Some of the organic matter becomes food for aquatic vegetation and animal
life ; some combines chemically with the oxygen of the air and water, forming inorganic compounds; more or less chemical change is due to the presence of microorganisms; while much of the solid matter is separated
and deposited in particles along the bed and banks of verted into intermittent filtration, effluent is to be discharged into a stream from which a filtration through the soil are the most free from or-
ganic matter. As the water passes through the soil, the organic matter is obstructed and retained, or taken water may become highly purified by this means,
though it is still uncertain whether water that has however, to notice that the managers of the Berlin the workmen are strietly forbidden to drink the water frols the sewage effluent, it is impossible to prevent In applying sewage to the soil for the purpose of Broad irrigation is the most satisfactory and effectual variety of methods, differing more or less in detail, all of which consist, essentially, in applying the sewage in the soil for the growth of vegetation. This appears to
the be the most natural and economic method of sewage position and growth under natural conditions, and position and growth under natural conditions, and
utilizes by irrigation and fertilization the full econonic value of the sewage. As the almount of sewage that can be applied to a given area, hovever, without being method requires extensive areas; hence the name
broad irrigation. In the vicinity of large cities land is very valuable, and in order to require less areas, a me stated, however, that it may be seriously questioned utilized for irrigation than have yet been obtained in America, thus permitting the use of more valuable land for this purpose. In order that renewed supplies processes, the application of sewage, commonly spoken
of as the dose, must be intermittent. If, without regard to the requirements of vegetation, the amount Application to the soil is, beyond question, the most satisfactory and effectual means of purifying sewage. up by vegetable growth. Under favorable conditions, been contaminated by sewage can be rendered so pure
as to be safe for domestic use. It may be of interest, means of sewage purification yet tried, where sufficient whether greater profits cannot be obtained from land 
Intermittent filtration may be considered as copious $\mid$ moldboard; the others keep a watchful eye on the $/$ where the multitude of way stations and the sale of irrigation devoid of its utilitarian. features. Both up- road, and are ready at any moment to hurry forward full rate, half rate, quarter rate and round trip ticket ward and dow sewage is flooded upon ground that has been prepared puffing locomotive, then, even to this day, messengers In order to expedite matters in this regard, the Coin-

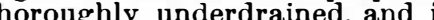
filtered by passing down ward through the soil to the drains. The filtration is not merely mechanical, how ever, but is largely a chemical process. While the soil, to some extent, acts as a mechanical filter in tion is chiefly of the of the solid matter, the purificavolving oxidation and nitrification, brought about argely through the agency of micro-organisms called bacteria, contained in the sewage.

It is thus seen that the sewage contains within itsel the means of its own purification, and, when the proper conditions are present, virtually becomes its own puriermitent filtration, purification is effected by the bacteria : and these minute organisms, having performed their important work, finally succumb to the action of oxygen and wholly disappear. If the filter beds are properly prepared and the application of sewage properly regulated, the beds will not become culed and inerly regulated, the

ough pertaining to an unattractive teresting of nature's processes; they are worthy of more attention than they have received, and should be more fully investigated and more generally understood. The whstrate, too, the universal principle slugoard. Every individual entity, however minute has its work to perform, and, having completed that work, the inflexible laws of nature's economy requir that it shall no longer exist in that particular form existence in which it nay again be useful.

THE NEW SNOW-PLOW OF THE RH ÆTIAN RAILWAY.

DURING one of the snowy winters shortly after the completion of the narrow railway which follows the road upward to Davos in the beautiful valley of Landquart, strong battalions of laborers had to be telegraphed for to Prätigau and the neighboring valleys 'The first snow-plow of the Landquart-Davos railroad was built of wood of the Landquart-Davos railroad cellent service on level surfaces : but against great ba ricades of snow thousands of yards in length it could make no impression. For this reason the plow was covered with iron plates, and in order that it might cut a still broader passage than heretofore, adjustable iron moldboards were added and a protecting roof built an ine thick and the weipht of the whole plow was ncreased to 33,000 pounds. Manual labor was now required only when the plow and its driving locomotive were stuck fast in a snow bank. After the continuation of the Rhretian railway of Davos-Landquart be ond Chur to Thusis, the directors of the road decided yo employ a second plow constructed entirely of iron, wiss Locomotive Works in Winterthur. This second plow illustrated in our engraving, weighs 24,948 pounds, ost $\$ 2,700$, and, after a most satisfactory trial, entered Dakos-Platz on December 7, 1897. Its adjustable mold boards are alnost six and one-half feet in height and When clear a road to a maximum breadh of 12136 feet. When work the well heated car behind the plow sits the engineer,

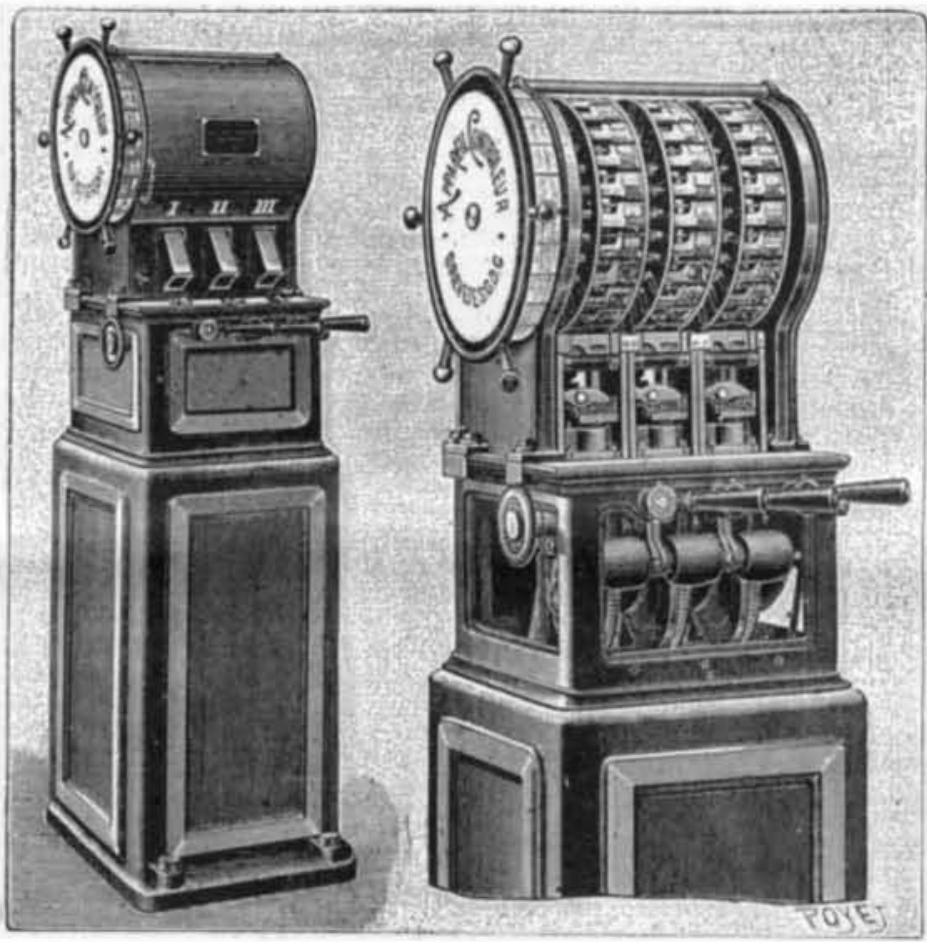

Fig. 1.-APPARATUS FOR DISTRIBUTING RAILROAD TICKETS.

pre to work their way in both directions in order to |pagnie des Chemins de Fer du Nord and the Compag procure much needed assistance.-Illustrirte Zeitung. $\begin{aligned} & \text { nie de l'Ouest have recently placed on trial a new and } \\ & \text { ingenious apparatus designed to distribute first, second }\end{aligned}$

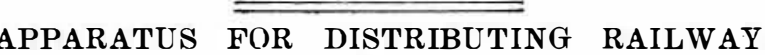
TICKETS.

As well known, in order to purchase a ticket at a A

PARIS-NORD 12E BAU

$301297 \quad 11$

DEUXIEME CLASSE

PLACE ENTIERE

CANAL

PRIX 0.55

\section{3}

5501

TICKET DELIVERED BY THE APPA BY IT. and third-class tickets upon short lines.
In order to complete the series of tickets mentioned above, it would be necessary to juxtapose several ap paratus. The general principle of the device is, briefly, cylinder around which are wound strips of cardboar and which is revolved by a wheel placed at the lef

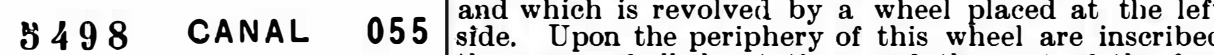
5499 CANAL 055 the naules of all the stations and the cost of the fare 4167 LA HAIE 050 lired, the wheel is revolved until the name of the place 0192 CHEM. FILL. 050 to which the traveler wishes to go presents itself oppo5500 CANAL 055 then depresses one of the three handles placed in front. \%5 01 CANAL 055 lardboard in the interior inmuediately detaches itsel 3302 CANAL 055 the name of the starting point, the date, month, year, 0193 CHEM. FILL, 050 hrice, the and place of destination, as well as th Then the band is cut and the ticket drops. As may be
Then 9082 LE LANDY 030 seen from this simple enumeration, the ticket carrie

2333 LUXEMB. 030 all the indications that are necessary. In Fig. 2 , to the left, is represented a ticket with all
the details just mentioned. The manipulation is very the details just mentioned. The manipulation is very point on the line very easily and very quickly.
This apparatus, in addition to the great services that

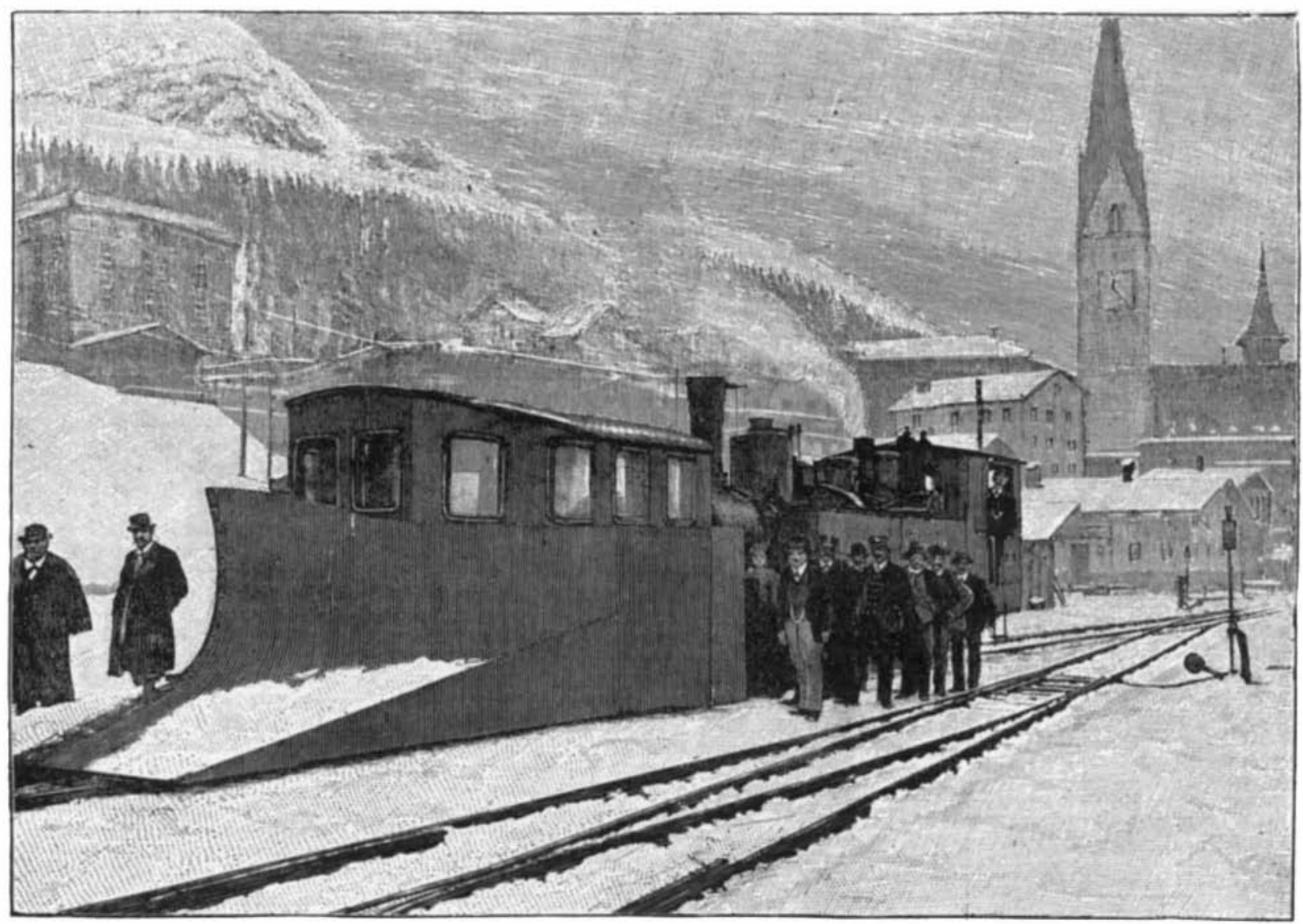

THE NEW SNOW.PLOW OF THE RHæTIAN RAILWAY

lis watchful eye constantly fastened upon the snow- fall into line behind a number of others and await his it renders as a distributer of tickets, acts as a registercorered road before him; without changing his place. colleague in the locoutive behind of ttube to his seems to pass slowly, the handig out of the tickets is, ticket all prepared, with the colleague in the locombtive behind. Of the men who nevertheless, done pretty rapidly, considering the num- strip of paper unwinds and receives the series number
assist him, two attend to the heavy inechanism of each ber and variety cold. On some of the Freneh dines, of the ticket, the place of destination and the price 